\title{
Guidance of longitudinally projecting axons in the developing central nervous system
}

\author{
Nozomi Sakai ${ }^{1}$ and Zaven Kaprielian ${ }^{1,2 *}$ \\ Dominick P. Purpura Department of Neuroscience, Albert Einstein College of Medicine, Bronx, NY, USA \\ 2 Department of Pathology, Albert Einstein College of Medicine, Bronx, NY, USA
}

\author{
Edited by: \\ Joshua A. Weiner, The University of \\ lowa, USA \\ Reviewed by: \\ Patricia Maness, University of North \\ Carolina, USA \\ Esther Stoeckli, University of Zurich, \\ Switzerland \\ *Correspondence: \\ Zaven Kaprielian, Dominick \\ P. Purpura Department of \\ Neuroscience and Department of \\ Pathology, Albert Einstein College of \\ Medicine, 1410 Pelham Parkway \\ South, Bronx, NY 10461, USA. \\ e-mail: zaven.kaprielian@ \\ einstein.yu.edu
}

\begin{abstract}
The directed and stereotypical growth of axons to their synaptic targets is a crucial phase of neural circuit formation. Many axons in the developing vertebrate and invertebrate central nervous systems (CNSs), including those that remain on their own (ipsilateral), and those that cross over to the opposite (commissural), side of the midline project over long distances along the anterior-posterior (A-P) body axis within precisely positioned longitudinally oriented tracts to facilitate the transmission of information between CNS regions. Despite the widespread distribution and functional importance of these longitudinal tracts, the mechanisms that regulate their formation and projection to poorly characterized synaptic targets remain largely unknown. Nevertheless, recent studies carried out in a variety of invertebrate and vertebrate model systems have begun to elucidate the molecular logic that controls longitudinal axon guidance.
\end{abstract}

Keywords: longitudinal axon guidance/targeting, Robo, CAMs, Sema, Wnt

\section{INTRODUCTION}

Longitudinally projecting axons connect different regions of the central nervous system (CNS) by extending over long distances along the anterior-posterior (A-P) body axis. Here, we review recent evidence supporting in vivo roles for long- and short-range guidance systems in regulating the pathfinding of longitudinally projecting ipsilateral and commissural axons. We first examine dye tracing and reporter gene expression data that reveal a previously unanticipated diversity and complexity of commissural and ipsilateral projections, which originate from neurons in the spinal cord and project longitudinally in the marginal zone; the outermost layer of the spinal cord proper that surrounds the gray matter. We then consider the reported roles of the morphogens, Sonic hedgehog (Shh) and Wnts, and potential interplay between these factors, in regulating the rostrally directed turn executed by post-crossing spinal commissural axons immediately after they cross the midline. Next, we address how Robo-Slit signaling, operating on its own or, potentially, in conjunction with particular cell adhesion molecules (CAMs), directs decussated commissural and ipsilateral axons into longitudinal tracts in the vertebrate CNS. We also evaluate the likely possibility that invertebrate model systems use a conserved set of, as well as unique, guidance cues and their receptors to ensure that commissural and ipsilateral axons are properly organized into stereotypically arranged longitudinal-oriented fascicles. In addition, we consider the mechanisms that appear to control the pathfinding of longitudinally projecting commissural and ipsilateral axons, which emanate from neurons located in various brain regions and descend into the spinal cord. Finally, we briefly discuss the few studies aimed at identifying the synaptic targets of genetically distinct populations of neurons/axons in the vertebrate CNS.

\section{PATHFINDING OF LONGITUDINALLY PROJECTING AXONS IN VERTEBRATES: ASCENDING SPINAL PROJECTION AND DESCENDING MIDBRAIN NEURONS SPATIAL ORGANIZATION OF LONGITUDINAL AXON TRACTS WITHIN THE SPINAL CORD MARGINAL ZONE}

By extending over long distances along the antero-posterior (A-P) axis of the CNS, ascending and descending spinal projection neurons transmit information to the brain and spinal cord, respectively. In vertebrates, projection neuron axons are contained within the spinal cord marginal zone (Figure 1). These axons assemble into longitudinal tracts or fascicles that are spatially organized in register with the positions of their brain targets (ascending axons) or brain origins (descending axons) in the spinal cord marginal zone (Burt, 1993; Brodal, 1998). Numerous anatomical and physiological studies have characterized the relative positioning of particular ascending and descending tracts within the spinal cord marginal zone (Burt, 1993; Brodal, 1998). For example, with specific regard to ascending projections, the spinothalamic tract is a major component of anterolateral system, which is housed within the ventral funiculus (VF) and ventrolateral funiculus (vLF) (Kerr, 1975; Giesler et al., 1981; Björkeland and Boivie, 1984; Willis, 2007). On the other hand, the spinocerebellar tract represents the predominant ascending pathway and is formed by axons located within both the dorsolateral funiculus (dLF) and the vLF (Xu and Grant, 1994, 2005; Willis, 2007). In addition, the dorsal funiculus (DF) contains the fasciculus gracilis 


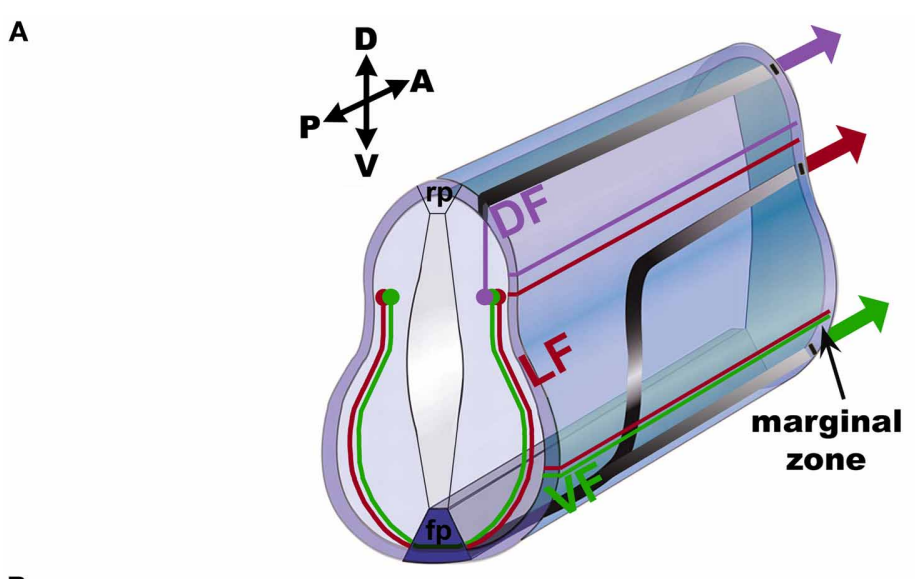

B

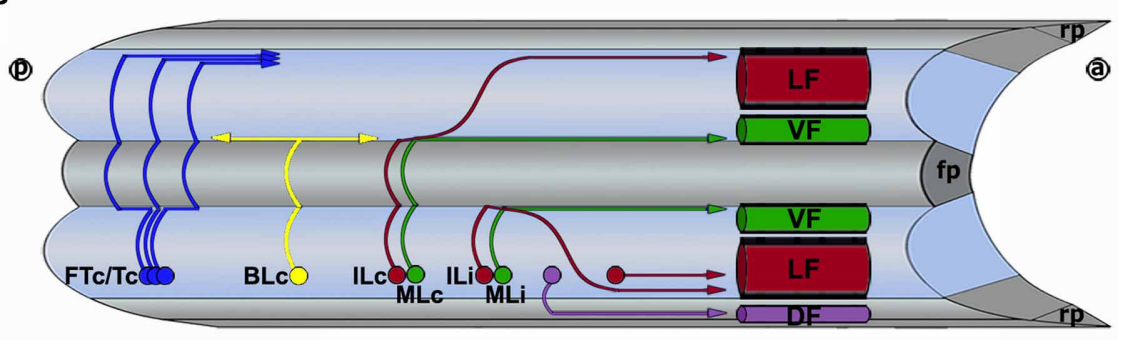

FIGURE 1 | Spinal axon trajectories within the vertebrate spinal cord. (A) Transverse view of the spinal cord shows ipsilaterally and contralaterally projecting axons growing within the spinal gray matter and, subsequently, the right side of the marginal zone. The axons of red neurons grow alongside the floor plate (fp), and project into the lateral funiculus (LF) of the spinal cord marginal zone, along either Intermediate Longitudinal commissural (ILC) or Intermediate Longitudinal ipsilateral (ILi) trajectories. The axons of green neurons extend adjacent to the $\mathrm{fp}$ along either Medial Longitudinal commissural (MLc) or Medial Longitudinal ipsilateral (MLi) trajectories to form the ventral funiculus (VF). The axons of purple neurons project ipsilaterally and dorsally to form the dorsal funiculus (DF) together with a subset of DRG axons (not shown). The cell body locations do not necessarily represent their settling positions. A, anterior; $\mathrm{P}$, posterior; $\mathrm{D}$, dorsal; $\mathrm{V}$, ventral; $\mathrm{rp}$, roof plate. (B) Open book view of the spinal cord shows the trajectories of unilaterally labeled axons. Commissural axons cross the floor plate ( $\mathrm{fp}$ ) and elaborate Forked Transverse commissural (FTc), Transverse commissural (Tc), Bifurcating Longitudinal commissural (BLC), ILc, and MLc projections. Ipsilaterally projecting axons remain on the same side of the CNS as their cell bodies and elaborate ILi and MLi projections. Ipsilaterally projecting axons can also directly project to the LF or to the dorsal funiculus (DF). Each of the depicted trajectories are present from thoracic to lumber levels of the spinal cord, and the locations of neuronal cell bodies do not necessarily represent their settling positions. (a), anterior; (D), posterior; rp, roof plate. and the fasciculus cuneatus, which terminate in the medulla oblongata (Giesler et al., 1984).

\section{DIVERSITY OF CONTRALATERAL COMMISSURAL AND IPSILATERAL PROJECTIONS IN THE VERTEBRATE SPINAL CORD}

Although the spatial arrangement of longitudinally projecting tracts within the spinal cord marginal zone has long been appreciated, the trajectories that the component axons adopt in the spinal cord proper, and which presumably prefigure this organization, have only recently been characterized. Since most ascending and descending tracts are comprised of both ipsilateral and commissural projections, and given the bilateral symmetry of the spinal cord, "one-sided/unilateral" labeling strategies are required to visualize the individual axons or sets of axons contained within a particular tract and to clearly delineate its ipsilateral and commissural components. Utilizing the lipophilic axon-tracer, $1,1^{\prime}$-dioctadecyl-3,3,3',3' tetramethylindocarbocyanine perchlorate (DiI), unilateral labeling of open book spinal cord preparations derived from various age chick and mouse embryos was previously carried out to selectively characterize the projections elaborated by post-crossing commissural axons. Importantly, this unilateral labeling strategy provided unobstructed views of postcrossing commissural axons and revealed a previously unappreciated complexity and diversity in their projections within the spinal cord marginal zone (Imondi and Kaprielian, 2001; Kadison and Kaprielian, 2004).

All spinal commissural axons initially project to their common intermediate target, the floor plate located at the ventral midline, along a simple linear pre-crossing trajectory (Bovolenta and Dodd, 1990; Imondi and Kaprielian, 2001) (Figure 1A). After crossing the floor plate, the contralateral segments of decussated commissural axons adopt at least five distinct trajectories (Figure 1B). The most commonly observed contralateral projections are elaborated by medial longitudinal commissural (MLc) axons, which extend in the longitudinal plane alongside the floor plate at the ventral midline and join/form the VF, and intermediate longitudinal commissural (ILc) axons, which initially grow alongside the floor plate and then project laterally, away from the ventral midline along an arcuate trajectory and ultimately turn longitudinally to form the LF (Bovolenta and Dodd, 1990; Imondi 
and Kaprielian, 2001; Kadison and Kaprielian, 2004). After turning into the longitudinal plane most MLc and ILc axons project rostrally, however, a minor but significant subset of each population extends in the caudal direction (Bovolenta and Dodd, 1990; Kadison and Kaprielian, 2004). The other three, relatively minor projections are elaborated by: bifurcating longitudinal commissural (BLc) axons, which bifurcate into rostrally and caudally projecting branches either within the VF alongside the FP or at a significant lateral distance from the spinal cord, where they contribute to the LF, forked transverse commissural (FTc) axons, which bifurcate on the ipsilateral side first, cross the floor plate, project transverse to the floor plate, and appear to join the LF or DF, or transverse commissural (Tc) axons, which do not turn in the VF but, rather, project transverse to the floor plate, and likely join the LF and DF (Bovolenta and Dodd, 1990; Kadison and Kaprielian, 2004).

Over the past 10 years, the emergence of in ovo and in utero electroporation technologies, together with the development of a wide range of reporter constructs, has made it possible to visualize axon pathfinding in both the embryonic chick and mouse spinal cord (Krull, 2004; Saito, 2006). Most importantly, unilateral in ovo electroporation has been used to reproducibly label genetically distinct populations of spinal axons and to assess potential differences in the trajectories elaborated by specific spinal neuron populations. For example, dorsal spinal neurons, which represent a major class of projection neurons (Nunes and Sotelo, 1985; Burstein et al., 1990; Yezierski and Mendez, 1991; Brodal, 1998), have been classified according to the particular transcription factor(s) they express (Helms and Johnson, 2003), and it has become possible to selectively visualize their pathfinding axons by electroporating reporter constructs harboring enhancer elements derived from the corresponding genes (Lumpkin et al., 2003; Nakada et al., 2004; Reeber et al., 2008; Avraham et al., 2009, 2010). These genetic labeling studies have revealed that the majority of $\mathrm{d} 1$ and $\mathrm{d} 2$ commissural axons adopt MLc and ILc trajectories and join the VF and LF, respectively, (Reeber et al., 2008; Avraham et al., 2009).

In addition to characterizing contralateral commissural projections, DiI tracing and unilateral in ovo electroporation of specific reporter constructs have also been used to identify three major projections elaborated by ipsilateral spinal neurons/axons. Specifically, major subsets of ipsilaterally projecting axons contribute to particular funiculi within the spinal cord marginal zone: (1) medial longitudinal ipsilateral (MLi) axons, which project along MLc axon-like trajectories, join the VF (Avraham et al., 2010), (2) intermediate longitudinal ipsilateral (ILi) axons, analogous to ILc axons, initially extend toward the ventral midline and then project away from the FP along an arcuate trajectory, or by directly projecting into lateral regions of the spinal cord, join the LF (Kadison and Kaprielian, 2004; Avraham et al., 2010), and (3) a subset of ipsilateral axons projects toward the marginal zone and turns into the longitudinal plane between the dorsal midline and the dorsal root, and join the DF (Avraham et al., 2010).

Whereas most spinal projection neurons extend ascending axons to the brain, some populations of spinal cord interneurons make local connections in segments located either above or below their cell bodies (Brodal, 1998; Kullander et al., 2003; Kiehn,
2006). Accordingly, DiI tracing and genetic labeling studies have identified a subset of caudally extending axons that contribute to the VF, LF and/or DF (Bovolenta and Dodd, 1990; Kadison and Kaprielian, 2004; Reeber et al., 2008; Avraham et al., 2009, 2010).

\section{THE ROLE(S) OF MORPHOGENS IN DIRECTING THE ROSTRAL TURN EXECUTED BY DECUSSATED SPINAL COMMISSURAL AXONS}

As described above, many commissural axons turn rostrally into the longitudinal plane after crossing the ventral midline. It has now become apparent that morphogens, once thought to exclusively control patterning events in the developing nervous system, regulate this key pathfinding decision faced by newly decussated commissural axons (Bovolenta, 2005; Charron and TessierLavigne, 2005; Zou and Lyuksyutova, 2007; Sánchez-Camacho and Bovolenta, 2009). For example, Wnt4 (see Table 1) appears to have a critical role in controlling the rostral turn executed by MLc and ILc axons in the mouse spinal cord (Lyuksyutova et al., 2003). This is supported by the finding that floor plate expresses Wnt4 mRNA in a rostral (high) to caudal (low) gradient in mouse embryos, and that Wnt4-expressing cells attract decussated commissural axons in vitro (Lyuksyutova et al., 2003). In addition, mice lacking a Wnt receptor and the well-known planar cell polarity signaling molecule, Frizzled3, display a reduction in the number of DiI-labeled rostrally growing decussated axons (Lyuksyutova et al., 2003). Other planar cell polarity components, including Drosophila van Gogh ortholog Vangl2 and Flamingo ortholog Celsr3 (Tissir and Goffinet, 2010), determine the rostrocaudal polarity of axon growth by interacting with Frizzled3 (Shafer et al., 2011). Accordingly, it appears that Wnt4 and/or its receptor Frizzled3, as well as Vangl2 and Celsr3 have a major role in regulating the polarity of the stereotypical rostral turn executed by ascending post-crossing commissural axons.

In the chick spinal cord, the potent morphogen, Shh, which is selectively expressed at the ventral midline, also has an important role in regulating the rostral turning of post-crossing commissural axons (Bourikas et al., 2005). Contrasting the pattern of Wnt4 expression described in mouse embryos, Shh is expressed by floor plate cells in a caudal (high) to rostral (low) gradient in chick embryos. Accordingly, it has been proposed that Shh operates as a repellent for post-crossing commissural axons as they project along the A-P axis of the spinal cord. Supporting this notion, knock down of Shh expression through the use of long double-stranded RNA interference (dsRNAi) causes stalling of decussated DiI-labeled axons in the vicinity of the floor plate, and prevents them from turning in the rostral direction (Bourikas et al., 2005). Interestingly, although Wnt4 is not present within the floor plate of the chick spinal cord, a non-graded distribution of $W n t 5 a$ and $W n t 7 a$ mRNA has been detected at the ventral midline (Domanitskaya et al., 2010). In addition, a Wnt antagonist, Secreted frizzled-related protein 1 (Sfrp1) mRNA is expressed within the floor plate, in an increasing rostrocaudal gradient, and ectopic expression of Shh induces Sfrp1 expression. Together these intriguing observations raise the possibility that Shh guides post-crossing spinal commissural axons in the rostral direction, by inducing an attractive Wnt gradient in the chick spinal cord (Domanitskaya et al., 2010). 
Table 1 | Selected molecules associated with the pathfinding of longitudinally projecting axons.

\begin{tabular}{|c|c|c|c|}
\hline Name & Organism & Localization $^{\mathrm{a}}$ & Suggested role in longitudinal guidance \\
\hline Celsr3 & Mouse & $\begin{array}{l}\text { Spinal commissural axons; mdDA and } \\
\text { hindbrain 5-HT axons }\end{array}$ & $\begin{array}{l}\text { Rostral turn of spinal commissural axons (Shafer et al., 2011); } \\
\text { rostrocaudal orientation of mdDA and hindbrain 5-HT axons } \\
\text { (Fenstermaker et al., 2010) }\end{array}$ \\
\hline EphA4 & Mouse & Corticospinal axons & $\begin{array}{l}\text { Prevents corticospinal axons from re-crossing in the spinal cord } \\
\text { (Dottori et al., 1998; Kullander et al., 2001b; Yokoyama et al., } \\
\text { 2001) }\end{array}$ \\
\hline ephrinB3 & Mouse & Ventral midline & $\begin{array}{l}\text { Midline barrier for corticospinal axons in the spinal cord } \\
\text { (Kullander et al., 2001a; Yokoyama et al., 2001) }\end{array}$ \\
\hline Fasll & Drosophila & Longitudinal axons & Fasciculation of Fasll+ longitudinal tracts (Lin et al., 1994) \\
\hline lin-17 (Frizzled) & C. elegans & Posterior dendrite of PLM neurons & $\begin{array}{l}\text { A-P orientation of PLM axon and dendrite (Hilliard and } \\
\text { Bargmann, 2006) }\end{array}$ \\
\hline $\begin{array}{l}\text { mig-1 } \\
\text { mom-5 (Frizzled) }\end{array}$ & C. elegans & $?$ & $\begin{array}{l}\text { Anterior orientation and growth of AVM and PVM longitudinal } \\
\text { axons (Pan et al., 2006) }\end{array}$ \\
\hline Frizzled3 & Mouse & $\begin{array}{l}\text { Spinal commissural axons; mdDA and } \\
\text { hindbrain 5-HT axons }\end{array}$ & $\begin{array}{l}\text { Rostral turn of spinal commissural axons (Lyuksyutova et al., } \\
\text { 2003); rostrocaudal orientation of mdDA and hindbrain 5-HT } \\
\text { axons (Fenstermaker et al., 2010) }\end{array}$ \\
\hline L1 & Mouse & Corticospinal axons at the pyramid & $\begin{array}{l}\text { Pyramidal decussation; facilitating caudal growth below the } \\
\text { pyramid (Cohen et al., 1997) }\end{array}$ \\
\hline N-cadherin & Drosophila & Longitudinal and commissural axons & $\begin{array}{l}\text { Fasciculation of Fasll }{ }^{+} \text {and Apterous longitudinal tracts (Iwai } \\
\text { et al., 1997) }\end{array}$ \\
\hline NCAM & Mouse & Corticospinal axons at the pyramid & $\begin{array}{l}\text { Pyramidal decussation; facilitating caudal growth below the } \\
\text { pyramid (Rolf et al., 2002) }\end{array}$ \\
\hline PSA-NCAM & Mouse & $\begin{array}{l}\text { Corticospinal axons in the pyramid and in } \\
\text { the DF }\end{array}$ & $\begin{array}{l}\text { Facilitates collateral formation by corticospinal axons (Daston } \\
\text { et al., 1996) }\end{array}$ \\
\hline Npn2 & Mouse & mdDA axons & $\begin{array}{l}\text { Directs mdDA axons along specific routes and to the prefrontal } \\
\text { cortex (Kolk et al., 2009; Yamauchi et al., 2009) }\end{array}$ \\
\hline PlexinA & Drosophila & Longitudinal axons & $\begin{array}{l}\text { Defasciculation of Fasll+ axons from intermediate to lateral } \\
\text { fascicle (Winberg et al., 1998) }\end{array}$ \\
\hline $\begin{array}{l}\text { PlexinA3 } \\
\text { PlexinA4 }\end{array}$ & Mouse & $\begin{array}{l}\text { (mRNA) corticospinal neurons; (PlexinA4 } \\
\text { mRNA) along the corticospinal tracts in } \\
\text { the hindbrain and inferior olive }\end{array}$ & Pyramidal decussation (Faulkner et al., 2008; Runker et al., 2008) \\
\hline PlexinB & Drosophila & $\begin{array}{l}\text { Intermediate and lateral region of } \\
\text { neuropile; Fas II+ intermediate fascicle }\end{array}$ & $\begin{array}{l}\text { Positioning and formation of Fas }\left.\right|^{+} \text {intermediate fascicle (Wu } \\
\text { et al., 2011) }\end{array}$ \\
\hline Robo1 & Mouse & Spinal commissural axons; descending & Dorsoventral positioning of longitudinal tracts formed by spinal \\
\hline Robo2 & Chick & $\begin{array}{l}\text { midbrain axons; ascending mdDA axons; } \\
\text { corticospinal and corticofugal tracts }\end{array}$ & $\begin{array}{l}\text { commissural axons (Reeber et al., 2008; Jaworski et al., 2010); } \\
\text { fasciculation and organization of midbrain and mdDA axon } \\
\text { tracts (Farmer et al., 2008; Dugan et al., 2011); restricting } \\
\text { mdDA, midbrain, corticospinal and corticofugal axons to the } \\
\text { ipsilateral side (Lopez-Bendito et al., 2007; Farmer et al., 2008; } \\
\text { Dugan et al., 2011) }\end{array}$ \\
\hline $\begin{array}{l}\text { Robo1 } \\
\text { Robo2 } \\
\text { Robo3 }\end{array}$ & Drosophila & Longitudinal axons in ventral nerve cord & $\begin{array}{l}\text { Mediolateral positioning of longitudinal tracts (Rajagopalan et al., } \\
\text { 2000; Simpson et al., 2000; Spitzweck et al., 2010) }\end{array}$ \\
\hline Ryk & Mouse & Corticospinal axons & $\begin{array}{l}\text { Facilitates the caudal growth of corticospinal tract (Liu et al., } \\
\text { 2005) }\end{array}$ \\
\hline Sema1A & Drosophila & Longitudinal and commissural axons & $\begin{array}{l}\text { Defasciculation of Fasll+ axons from intermediate to lateral } \\
\text { fascicle (Yu et al., 1998) }\end{array}$ \\
\hline Sema2A & Drosophila & $\begin{array}{l}\text { Midline and commissure in the ventral } \\
\text { nerve cord }\end{array}$ & $\begin{array}{l}\text { Repulsive boundary for positioning and growth of Fas II+ } \\
\text { intermediate fascicle (Wu et al., 2011) }\end{array}$ \\
\hline Sema2B & Drosophila & $\begin{array}{l}\text { Medial and intermediate region of } \\
\text { neuropile; Fas } \mathrm{I}^{+} \text {intermediate fascicle }\end{array}$ & Fasciculation of Fasll+ intermediate fascicle (Wu et al., 2011) \\
\hline Sema3F & Mouse & Midbrain-hindbrain border & $\begin{array}{l}\text { Directs mdDA axons rostrally (Yamauchi et al., 2009); directs } \\
\text { mdDA axons to the prefrontal cortex (Kolk et al., 2009) }\end{array}$ \\
\hline
\end{tabular}


Table 1 | Continued

\begin{tabular}{|c|c|c|c|}
\hline Name & Organism & Localization $^{a}$ & Suggested role in longitudinal guidance \\
\hline Sema6A & Mouse & $\begin{array}{l}\text { (mRNA) along the corticospinal tracts in } \\
\text { the hindbrain and inferior olive }\end{array}$ & Pyramidal decussation (Faulkner et al., 2008; Runker et al., 2008) \\
\hline Sfrp1 & Chick & (mRNA) ventral midline & $\begin{array}{l}\text { Regulates rostral turn of spinal commissural axons by } \\
\text { antagonizing Wnt5a and Wnt7a (Domanitskaya et al., 2010) }\end{array}$ \\
\hline Shh & Chick & Ventral midline & Rostral turn of spinal commissural axons (Bourikas et al., 2005) \\
\hline Slit1 & Mouse & (mRNA) ventral midline; (Slit1 and Slit2 & Positioning of longitudinal spinal axon tracts (Long et al., 2004); \\
\hline Slit2 & & mRNA) forebrain-midbrain border and & fasciculation and organization of longitudinal midbrain and \\
\hline Slit3 & & ventral forebrain structures & $\begin{array}{l}\text { mdDA axon tracts (Farmer et al., 2008; Dugan et al., 2011); } \\
\text { forming the ventral midline boundary in the brain (Bagri et al., } \\
\text { 2002; Farmer et al., 2008; Dugan et al., 2011) }\end{array}$ \\
\hline Unc5c & Mouse & (mRNA) cerebral cortical layer $\mathrm{V}$ and $\mathrm{VI}$ & Pyramidal decussation (Finger et al., 2002) \\
\hline Vangl2 & Mouse & $\begin{array}{l}\text { mdDA and hindbrain } 5-\mathrm{HT} \text { axons; (mRNA) } \\
\text { spinal cord gray matter }\end{array}$ & $\begin{array}{l}\text { Rostral turn of spinal commissural axons (Shafer et al., 2011); } \\
\text { rostrocaudal orientation of mdDA and hindbrain 5-HT axons } \\
\text { (Fenstermaker et al., 2010) }\end{array}$ \\
\hline egl-20 (Wnt) & C. elegans & Tail & $\begin{array}{l}\text { Anterior orientation and growth of AVM and PVM longitudinal } \\
\text { axons via repulsion (Pan et al., 2006) }\end{array}$ \\
\hline lin-44 (Wnt) & C. elegans & Posterior epidermal cells & $\begin{array}{l}\text { A-P orientation of PLM axon and dendrite (Hilliard and } \\
\text { Bargmann, 2006) }\end{array}$ \\
\hline Wnt1 Wnt5a & Mouse & $\begin{array}{l}\text { (mRNA) dorsal spinal gray matter; (Wnt5a } \\
\text { mRNA) ventral midline in the brain }\end{array}$ & $\begin{array}{l}\text { Repels corticospinal tract in vitro (Liu et al., 2005); (Wnt5a) initial } \\
\text { rostral bias of mdDA axon projection (Fenstermaker et al., } \\
\text { 2010) }\end{array}$ \\
\hline Wnt4 & Mouse & (mRNA) ventral midline & $\begin{array}{l}\text { Attracts spinal commissural axons rostrally in vitro (Lyuksyutova } \\
\text { et al., 2003) }\end{array}$ \\
\hline Wnt5a Wnt7a & Chick & (mRNA) ventral midline & $\begin{array}{l}\text { Rostral turn of spinal commissural axons (Domanitskaya et al., } \\
\text { 2010) }\end{array}$ \\
\hline
\end{tabular}

a Protein localization unless otherwise stated (i.e., mRNA).

Given that a subset of the ipsilaterally extending axons also project to the brain along MLi and ILi trajectories (see above), it would be interesting to determine whether ventral midlineassociated Wnts and Shh regulate the rostral turn executed by these subsets of ascending axons. The findings of such experiments could conceivably reveal a previously unsuspected heterogeneity in the response of commissural and ipsilateral axons to morphogens that control the polarity of longitudinally projecting axons.

\section{ORGANIZATION OF LONGITUDINAL AXON TRACTS: THE ROLE(S) OF ROBO-SLIT SIGNALING}

After executing rostral or caudal turns into the longitudinal plane at various positions along the A-P axis of the CNS, the axons of both ascending and descending projection neurons are sorted into discrete longitudinal bundles or tracts located at specific distances form the midline (Burt, 1993; Brodal, 1998). In the vertebrate spinal cord, Robo receptors and their Slits ligands have well-established and critical roles in regulating the positioning of contralaterally ascending spinal commissural axon-containing longitudinal tracts (Dickson and Gilestro, 2006; Dickson and Zou, 2010). For example, Robo-Slit signaling normally drives spinal commissural axons along ILc trajectories and into the LF in the embryonic chick spinal cord (Reeber et al., 2008). By disabling Robo-Slit signaling via unilateral electroporation of spinal commissural neurons with cytoplasmic truncations (dominant-negative forms) of Robol or Robo2, a striking and selective axon pathfinding phenotype was observed: post-crossing commissural axons failed to elaborate ILc projections and, instead, exclusively extended along MLc-like trajectories, forming a hyperfasciculated, inappropriately thick VF (Reeber et al., 2008). Essentially all of the spinal commissural axons transfected with Robo dominant-negative constructs, including those extended by $\mathrm{d} 1$ and $\mathrm{d} 2$ neurons, and both ascending and descending axons, exhibited this phenotype (Reeber et al., 2008). Similarly in the mouse spinal cord, the number of DiI-labeled ILc axons is reduced in the spinal cord of Robo2 null and Robo1; Robo2 double mutant mice (Jaworski et al., 2010). In addition, the expression of L1, which is a general marker for longitudinally projecting spinal axons (Imondi et al., 2000), in the spinal cord of mice lacking all three Slits, Slits1-3, revealed a reduction in the width of the LF (Long et al., 2004). Together, these observations support the view that Robo-Slit signaling has a major role in directing spinal commissural axons into the LF.

Robo-Slit signaling also appears to have a role in regulating the pathfinding of longitudinally projecting descending axons, which emanate from particular midbrain neurons. For example, analyses of various knockout mice have shown that Robo-Slit interactions normally prevent a variety of DiI-labeled descending axons from inappropriately crossing the midline in the brain (Bagri et al., 2002; Lopez-Bendito et al., 2007; Farmer et al., 2008). It is interesting to note in this regard that roles for Robos and Slits in barring longitudinally projecting spinal axons from the midline have not been clearly defined in the chick and mouse spinal cord. 
For example, in chick embryos, spinal (commissural and ipsilateral) axons mis-expressing dominant-negative forms of Robo do not ectopically cross the ventral midline (Reeber et al., 2008). Similarly, the re-crossing of spinal commissural axons has not been observed in Robo1; Robo2 double null mutant mice (Jaworski et al., 2010). In addition, whereas midline re-crossing events have been observed in mice lacking all three Slits, these apparently occur before the decussated axons turn into the longitudinal plane (Long et al., 2004). Therefore, the factors/mechanisms that prevent ascending spinal axons from invading the ventral midline have not been identified.

Consistent with additional roles for Robo-Slit signaling in the pathfinding of descending axons, the longitudinal tracts in the brain, which they normal assemble into, are disorganized or defasciculated in mice lacking Robos or Slits (Lopez-Bendito et al., 2007; Farmer et al., 2008). For example, in mouse embryos, Robo-Slit signaling is required for organizing ipsilateral descending axons extended by midbrain neurons within longitudinal fascicles, but not the dorsoventral positioning of these fascicles (Farmer et al., 2008). Although the ventral-most medial longitudinal fascicle invades the ventral midline in the midbrain and hindbrain of Slit1; Slit2 and Robo1; Robo2 double mutants, resulting in a ventral shift of this tract, the other two lateral tracts do not shift ventrally or fasciculate into one large bundle (Farmer et al., 2008). This contrasts with the ventral shift of the spinal commissural axon-containing LF observed in mice lacking Robos/Slits. Whereas both ascending spinal commissural axons and ipsilaterally descending midbrain axons appear to rely on Slits at the ventral midline, the roles of Robo-Slit signaling are clearly model system-specific. These differences might be due to distinct sources of Slits, different downstream signaling systems and/or the presence of non-canonical signaling molecules, which interact with Robo-Slit signaling system.

\section{PATHFINDING OF LONGITUDINAL AXONS IN VERTEBRATES: MIDBRAIN/FOREBRAIN DOPAMINERGIC TRACTS}

In vertebrates, longitudinal axons emanating from spinal projection neurons pathfind through a rather homogenous spinal cord environment, which lacks conspicuous cellular specializations or choice points that could act as intermediate targets, before reaching the brain. In contrast, longitudinal axons originating from the neurons in higher brain areas encounter many distinct structures, which could act as guideposts and sources of key guidance cues, as they project to their appropriate synaptic targets. Therefore, the role of intermediate targets in regulating the pathfinding of longitudinal axons can often be more clearly delineated in the brain. One of the most prominent longitudinal tracts in the brain is the ascending mesodiencephalic dopaminergic (mdDA) pathway, which originates from dopaminergic neurons in the substantia nigra and ventral tegmental area in the midbrain and forebrain, and projects to the striatum as well as the cortex in the forebrain (Bjorklund and Dunnett, 2007).

\section{ESTABLISHING THE ROSTROCAUDAL POLARITY OF mdDA AXONS}

Several independent studies have shown that canonical axon guidance molecules, in particular, Semaphorin-3F (Sema3F) regulates various aspects of mdDA axon pathfinding via its receptor,
Neuropilin-2 (Npn2), which is expressed on these axons (Kolk et al., 2009; Yamauchi et al., 2009). Initially, Sema3F, which is present at the midbrain-hindbrain boundary caudal to a subpopulation of mdDA cell bodies, appears to direct ascending mdDA axons rostrally by operating as a repulsive guidance cue (Yamauchi et al., 2009). A subset of mdDA axons, labeled by an antibody against tyrosine hydroxylase $(\mathrm{TH})$, inappropriately projects caudally in Npn2 mutant mice, supporting the role of Sema3F-Npn2 in establishing the initial rostrocaudal polarity of this projection (Yamauchi et al., 2009). It is interesting to note in this regard that $S e m a 3 F$ expression at the midbrainhindbrain boundary might be controlled by the morphogen, fibroblast growth factor 8 (Fgf8), since Ffg8-soaked beads can induce ectopic Sema3F mRNA expression and disrupt the rostral projection of mdDA axons, whereas reducing Fgf8 signaling using a Fgf receptor tyrosine kinase inhibitor eliminates Sema3F mRNA expression (Yamauchi et al., 2009).

Just as for ascending spinal commissural axons, Wnts and planar cell polarity signaling molecules appear to orient longitudinally projecting mdDA axons, as well as other monoaminergic neurons in the brain (i.e., serotonergic [5-HT] axons) (Fenstermaker et al., 2010). Here, in Wnt5a mutant, a small subset of ascending mdDA axons initially mis-projects caudally in E12.5 embryos although the phenotype is corrected by E17.5. In contrast, E17.5 mouse embryos lacking the planar cell polarity components, Frizzled3, Vangl2, or Celsr3, which are all expressed on ascending mdDA axons, exhibit more prominent and persistent aberrant caudal mis-projections (Fenstermaker et al., 2010). Hindbrain 5-HT axons also show aberrant rostrocaudal projections in these mutant mice (Fenstermaker et al., 2010). Whereas the rostrocaudal bias of mdDA and 5-HT axon projections appear to be established by Frizzled3, Vangl2, and Celsr3, the organization and/or orientation of these cell bodies are also disrupted in the corresponding mutants, thus, complicating phenotypic analyses. It will be important to examine the causal relations between the organization/orientation of mdDA cell bodies and axons, if these events are related.

\section{FASCICULATION OF mdDA AXONS}

Robo-Slit signaling has a critical role in regulating fasciculation and rostral growth of ascending mdDA axons (Bagri et al., 2002; Dugan et al., 2011). Slit1 and Slit2 mRNA are expressed at the ventral midline and within the hypothalamus in the forebrain, as well as at the forebrain-midbrain border (Bagri et al., 2002; Dugan et al., 2011). Normally, TH-labeled mdDA axons, which express Robo1 and Robo2, project rostrally in close proximity to these Slit1/Slit2-epressing ventral structures (Dugan et al., 2011). However, in both Slit1; Slit2 and Robo1; Robo2 double mutants at E12.5, the initial projection of mdDA axons is defasciculated and disorganized (Dugan et al., 2011). Many mdDA axons appear to inappropriately project toward the ventral midline, which expresses high levels of Slit1 and Silt2. One day later, at E13.5, although a subset of the defasciculated axons seems to recover and project in the appropriate direction within organized bundles, inappropriate invasion of the ventral midline is still evident and a part of the rostral track is hyperfasciculated, in both Robo and Slit double mutants (Dugan et al., 2011). In addition, Robo1; Robo2 
double mutants display dorsal mis-projections, which are not as prominent in Slit1; Slit2 mutants. Thus, some roles of Robo1 and Robo2 in orienting mdDA axons into the rostral track appear to be independent of Slits (Dugan et al., 2011). Taken together, it appears that Robo-Slit signaling is required for the fasciculation and organization of ascending mdDA tracts, and prevents these axons from crossing the ventral midline in the forebrain.

Sema3F-Npn2 signaling also appears to control fasciculation of TH-positive mdDA longitudinal tracts as they project rostrally, since these axons are observed to defasciculate in Sema3F or Npn2 mutant mice (Kolk et al., 2009). In addition, Npn2or Sema3F-independent phenotypes have been reported in mice lacking Sema3F or Npn2, respectively. In Sema3F mutants, a subset of the defasciculated mdDA axons mis-projects ventrally toward the lateral hypothalamus, whereas mdDA axons in Npn2 mutants follow an aberrant route to reach the prefrontal cortex (Kolk et al., 2009). Importantly, the targeting of these mdDA axons to the prefrontal cortex is disrupted in both Sema3F and Npn2 mutant mice, but in disparate ways. At E18.5, the number of mdDA axons innervating the target area of the prefrontal cortex is significantly reduced in Sema3F mutants, whereas the number of these axons projecting to the same target area is increased in Npn2 mutant mice (Kolk et al., 2009). Interestingly and likely reflecting an example of error correction, the majority of mdDA axons are reported to reach their appropriate target areas in adult Sema3F mutants (Kolk et al., 2009). Further studies focusing on elucidating the in vivo roles of Sema3F and Npn2 signaling, as well as considering the potential involvement of other Semas should help clarify these complicated phenotypes. Most importantly, understanding the underlying mechanisms that control the relevant pathfinding events should reveal the consequences of the targeting errors made by mdDA axons in mouse embryos lacking Sema3F or Npn2.

\section{PATHFINDING OF LONGITUDINAL AXONS IN VERTEBRATES: THE CORTICOSPINAL TRACT}

One of the longest longitudinal axon-containing projections in the vertebrate CNS is the corticospinal tract, which connects the cerebral cortex to the spinal cord. Perhaps due to the relative ease of unilaterally labeling the component axons from the cerebral cortex, the complete trajectory followed by corticospinal tract axons has been carefully mapped. These axons are extended by pyramidal neurons located in layer $\mathrm{V}$ of the cerebral cortex, remain ipsilateral with respect to the midline (Stanfield, 1992; Brodal, 1998), and descend in the ventral region of the cerebral peduncle, through midbrain and hindbrain until they reach the caudal-most portion of the hindbrain, where most of these axons cross the midline dorsally to the contralateral side, forming the $\mathrm{X}$-shaped pyramidal decussation. Corticospinal axons further project caudally within the marginal zone of the spinal cord, in a region containing the DF in rodents, and innervate neurons located within the spinal gray matter (Stanfield, 1992; Brodal, 1998).

\section{A ROLE FOR ROBO-SLIT SIGNALING IN REGULATING THE IPSILATERAL PROJECTION OF THE CORTICOSPINAL TRACT IN THE BRAIN}

As described above, the corticospinal tract initially projects in a purely ipsilateral manner within the brain. Accordingly, the mechanisms that maintain this laterality have a critical role in corticospinal tract formation. Slit1 and Slit2 mRNA are also expressed at the ventral midline of the forebrain, where these midline repellents create a barrier between the two sides of the rostral CNS (Bagri et al., 2002). Robo1 and Robo2 are expressed in particular populations of forebrain neurons/axons, including the major longitudinal projections that originate within the cortex, the corticospinal and corticofugal tracts (Lopez-Bendito et al., 2007), and Robo-Slit signaling prevents these tracts from crossing the midline in the forebrain (Bagri et al., 2002; LopezBendito et al., 2007). Specifically, in Robo1; Robo2 and Slit1; Slit2 double mutants, the majority of the DiI-labeled corticospinal tract-associated axons aberrantly cross the midline at rostral levels before they would normally turn into the longitudinal plane (Bagri et al., 2002; Lopez-Bendito et al., 2007). Some of these misguided axons re-cross to the ipsilateral side of the brain, whereas others continue projecting into the contralateral side of the telencephalon (Lopez-Bendito et al., 2007). Thus, Robo-Slit signaling prevents corticospinal axons from inappropriately crossing the midline in the forebrain.

\section{DECUSSATION OF THE CORTICOSPINAL TRACT}

The hindbrain pyramids represent the most conspicuous intermediate targets for longitudinally projecting corticospinal axons. Although several classes of molecules have been identified as candidates for regulating the decussation of corticospinal axons within this brain region, thus far, mainly contact-dependent, short-range guidance molecules have been directly implicated in this process.

Most notably, the immunoglobin cell adhesion molecule (IgCAM), L1, is required for corticospinal axons to cross the ventral midline in the hindbrain (Cohen et al., 1997; Dahme et al., 1997). Although corticospinal axons appear to normally descend in the hindbrain of $L 1$ mutant mice, a subset of these axons fails to cross the midline in the lower hindbrain and inappropriately projects both ipsilaterally and contralaterally (Cohen et al., 1997). Some of mis-routed axons project dorsally to the ipsilateral DF or remain ventrally positioned but turn into the longitudinal plane and project caudally in the ventrolateral edge of the ipsilateral side of hindbrain (Cohen et al., 1997). Moreover, the number of caudally projecting axons in the spinal cord is severely reduced in adult mutants. Since the number of normally decussated corticospinal commissural axons is also reduced in the spinal cord of L1 mutant mice, L1 might be required for the growth of these axons within the spinal cord. Although L1 is expressed on developing pyramidal fibers (Cohen et al., 1997), how L1 regulates the midline crossing of corticospinal axons remains to be determined. In this regard, it has been suggested that Sema3A secreted by the ventral spinal cord is capable of repelling cortical axons expressing L1 in vitro, and Neuropilin-1 (Npn1) and L1 form a receptor complex that likely transduces this Sema3A-mediated repulsive signal (Castellani et al., 2000). However, this is unlikely to be the mechanism underlying the formation of the pyramidal decussation, since corticospinal tracts form normally and on schedule in Sema3A mutant mice (Sibbe et al., 2007).

In addition to L1, another IgCAM, neural cell adhesion molecule (NCAM), has also been implicated in controlling the 
pyramidal decussation of corticospinal axons (Rolf et al., 2002). The corticospinal axon pathfinding defects observed in NCAM mutants resemble the $L 1$ mutant phenotype in that they reveal the lack of decussation in the hindbrain and bilateral caudal projections in the spinal cord of early postnatal mice. Unlike L1 mutant mice, however, only a small number of mis-routed axons are present on the ipsilateral side of the pyramid in NCAM adult mutants (Rolf et al., 2002). Whether these mis-projections were corrected or eliminated at later ages has not been investigated. Since corticospinal axons arrive later at the caudal hindbrain in NCAM mutant mice as compared to their wild type counterparts, the defects in corticospinal tracts appear to manifest themselves prior to the formation of the pyramidal decussation (Rolf et al., 2002).

The transmembrane Sema6A and its receptors PlexinA3 and PlexinA4 have also been implicated in regulating the decussation of corticospinal axons (Faulkner et al., 2008; Runker et al., 2008). In Sema6A single, PlexinA4 single and PlexinA3; PlexinA4 double mutant mice, corticospinal axons normally descend to the caudal hindbrain. Subsequently, however, some of these axons correctly decussate, but many others inappropriately projected to the ventrolateral edge of the ipsilateral hindbrain (Faulkner et al., 2008; Runker et al., 2008). Notably, however, the mis-guided axons continue projecting caudally (Faulkner et al., 2008; Runker et al., 2008). PlexinA3 and PlexinA4 mRNA is expressed by cortical neurons, and Sema6A and PlexinA4 mRNA are found along the terrain through which corticospinal axons project in the caudal hindbrain and in the inferior olivary nuclei, which is located adjacent and lateral to the corticospinal tract in the pyramid (Faulkner et al., 2008; Runker et al., 2008). Collectively the loss of function phenotypes exhibited by the various Sema and Plexin mutant mice suggest that Sema6A-PlexinA3/4 signaling-mediated repulsion normally drives corticospinal axons toward the midline where they undergo decussation (Faulkner et al., 2008; Runker et al., 2008).

A reduction in the size of the pyramidal decussation has been also reported in Netrin 1 receptor Unc5c (previously known as Unc5h3) mutant mice (Finger et al., 2002). The phenotypes observed in $U n c 5 c$ mutants most closely resemble those displayed by Sema6A and PlexinA3; PlexinA4 mouse mutants: the majority of corticospinal axons fail to cross the midline, and the misdirected axons continue projecting caudally in the lateral funiculus of the spinal cord. Moreover, these mis-routed corticospinal axons appear to fasciculate with each other in the lateral funiculus (Finger et al., 2002). Therefore, unlike in L1 and NCAM mutants, the caudal projection of mis-routed corticospinal axons in Sema6A, PlexinA3; A4, and Unc5c mutants is intact and possibly regulated by other molecules found in both the DF and lateral funiculus. Since CAMs are known to promote axon outgrowth (Raper and Mason, 2010), L1 and NCAM might, at least to some extent, facilitate the caudally directed growth of the corticospinal axons within the spinal cord. Alternatively, the differences between the phenotypes exhibited by the various mutant mice might simply reflect the different techniques and experimental approaches used to visualize corticospinal axons/tracts.

\section{CAUDAL GROWTH OF CORTICOSPINAL AXONS IN THE SPINAL CORD}

After crossing the midline within the caudal hindbrain, rodent corticospinal axons project caudally in the DF of the spinal cord (Stanfield, 1992). Consistent with Wnt4 being required for the polarity of ascending spinal commissural axons (Lyuksyutova et al., 2003), Wnt1 and Wnt5a have been implicated as regulators of the caudal growth displayed by corticospinal axons within the spinal cord (Liu et al., 2005). Support for this model comes from the finding that Wnt1 and Wnt5a mRNA is expressed in the dorsal spinal gray matter surrounding the DF in rostral (high) to caudal (low) gradients. In addition, the Wnt receptor, Receptor tyrosine kinase-related tyrosine kinase (Ryk)-like transmembrane receptor is expressed at high levels on corticospinal axons, and Wnt1/Wnt5a repel corticospinal axons expressing Ryk in vitro (Liu et al., 2005). Moreover, injection of a functional blocking anti-Ryk antibody into the cervical level spinal cord of neonatal mice retards the growth of descending corticospinal axons (Liu et al., 2005). With regard to these particular findings, it is important to note that the DF also contains the fasciculus gracilis and fasciculus cuneatus, which ascend from dorsal root ganglia to the lower hindbrain (Burt, 1993; Brodal, 1998). Thus, it would be interesting to determine whether Wnt1/Wnt5a facilitate the rostral growth of these dorsal-column-associated ascending axons, possibly through resident Wnt receptors that mediate attraction via Wnt gradients in the spinal cord. In addition, Ryk-mediated signaling through Wnts might be responsible for the caudal mis-projection of the corticospinal axons in mutant mice with pyramidal decussation defects, such as the Sema6A and Unc5c null mutants (Finger et al., 2002; Faulkner et al., 2008; Runker et al., 2008), mentioned above. Since Wnt1/Wnt5a mRNA expression is not present in the vicinity of the lateral funiculus (Liu et al., 2005), other Wnts found in this region could be presented to Ryk-bearing axons. In any case, assessing the role of Wnts in vivo might help to further understand the mechanisms that control the rostrocaudal polarity of corticospinal axons.

\section{PREVENTING CORTICOSPINAL AXONS FROM RE-CROSSING THE MIDLINE IN THE SPINAL CORD}

As reflected by the somatotopic organization of corticospinal neurons in the sensorimotor cortex, these descending axons innervate neurons at specific levels of the spinal cord (Stanfield, 1992; Kuang and Kalil, 1994). Upon reaching the appropriate rostrocaudal segments of the spinal cord, corticospinal axons project into the spinal gray matter, where they form connections with their specific synaptic targets (Stanfield, 1992; Brodal, 1998). Since corticospinal axons transmit signals from one side of the cerebral cortex to neurons located on the opposite side of the spinal cord, once they cross, these descending longitudinal axons must terminate on the contralateral side of the CNS and never re-cross the midline. Within the spinal cord gray matter, repulsive interactions between the EphA4 receptor tyrosine kinase and the transmembrane ephrinB3 ligands facilitate this pattern of innervation by preventing decussated corticospinal axons from re-crossing back to the ipsilateral side (Dottori et al., 1998; Kullander et al., 2001a; Yokoyama et al., 2001). EphrinB3 is selectively expressed at the ventral midline of the spinal cord and this short-range repulsive 
Eph ligand forms a boundary separating axons on either side of the spinal cord (Kullander et al., 2001a; Yokoyama et al., 2001). Corticospinal axons express one of the ehrinB3 receptors, EphA4, and thereby regulate ephrinB3-mediated repulsive signaling cell autonomously (Kullander et al., 2001b). In both ephrinB3 and EphA4 mutant mice, corticospinal axons normally cross at the caudal hindbrain and project caudally in the contralateral DF (Kullander et al., 2001a,b; Yokoyama et al., 2001). However, after these axons enter the spinal cord gray matter, some of them recross the midline and innervate targets on the ipsilateral side of the spinal cord (Kullander et al., 2001a,b; Yokoyama et al., 2001). Since the majority of re-crossing corticospinal axons enter the ipsilateral side of the CNS via the spinal cord gray matter rather than through the $\mathrm{DF}$, in ephrinB3 and EphA4 mutant mice (Kullander et al., 2001a,b), the laterality of descending longitudinal projections in the dorsal funiculi appears to be regulated by some other yet to be described mechanism. It is important to note that the midline barrier formed by ephrinB3 is critical for preventing the aberrant crossing of not only corticospinal axons, but also other EphA4-expressing axons in the spinal cord, such as those extended by ventral spinal interneurons (Kullander et al., 2003).

\section{PATHFINDING OF LONGITUDINAL AXONS IN THE INVERTEBRATE CNS THE ROLE OF Wnt-FRIZZLED SIGNALING IN C. elegans}

In a striking example of evolutionary conservation, morphogens also appear to control the guidance of longitudinally projecting axons along the A-P axis in invertebrates. Consistent with the likely role of Wnts in regulating the polarity of post-crossing spinal commissural axons in the embryonic mouse spinal cord (see above), Wnt-Frizzled signaling has a key role in regulating rostrocaudal pathfinding decisions made by longitudinally projecting axons in C. elegans. Specifically, Wnt (lin-44) via the Frizzled (lin-17) receptor regulates the A-P orientation of PLM mechanosensory axons and dendrites (Hilliard and Bargmann, 2006). PLM mechanosensory neurons are bipolar and Frizzled (lin-17) is highly expressed on posteriorly growing dendrites. This asymmetric expression of Frizzled (lin-17) receptors is induced by Wnt (lin-44) and thus, Wnt (lin-44) and Frizzled (lin-17) signaling regulate the A-P orientation of PLM neurons neither by repelling nor attracting these axons or dendrites. In addition to establishing the A-P orientation of axons, longitudinal projections of mechanosensory axons are guided by Wnt-Frizzled signaling in C. elegans (Pan et al., 2006). However, opposite to what has been observed in the mouse spinal cord, caudally expressed Wnt (egl-20) operates as a repellent via Frizzled (mig-1 and mom-5) signaling to direct longitudinally projecting axons rostrally in C. elegans (Pan et al., 2006). Thus, although the role of Wnt-Frizzled signaling in regulating A-P polarity is conserved between mammals and worms, the mechanistic details are distinct across species.

\section{THE ROLES OF ROBO RECEPTORS IN POSITIONING LONGITUDINAL TRACTS IN THE DROSOPHILA VENTRAL NERVE CORD}

Further consistent with evolutionarily conserved roles for guidance systems that control longitudinal axon pathfinding, the involvement of Robos in regulating the lateral positioning of longitudinally projecting axons tracts was first demonstrated in the Drosophila ventral nerve cord (Rajagopalan et al., 2000; Simpson et al., 2000). The expression patterns of the three Drosophila Robo receptors, Robo1-3, on longitudinal axons define distinct mediolateral zones in the neuropile of the ventral nerve cord; Robol is expressed on axons in the medial zone, the intermediate zone contains axons that express Robo1 and Robo3, and axons that express all three Robos are present in the lateral zone, and disrupting these collective expression patterns predictably perturbs the lateral positioning of longitudinal axons (Rajagopalan et al., 2000; Simpson et al., 2000). In addition to the pronounced midline re-crossing phenotype displayed by Robol, and occasionally Robo2, mutants, the loss of function phenotype of each Robo mutant is similar to the consequences of disabling Robo-Slit signaling in the vertebrate spinal cord; a major medial shift in the positioning of many longitudinal axons (see above). In particular, anti-Fasciclin II [FasII, marker of three major longitudinal tracts in the Drosophila CNS (Grenningloh et al., 1991)] labeling of intermediate fascicle reveals that the loss of Robo3 function results in an inappropriate fusion of these axons with the medial fascicle (Rajagopalan et al., 2000; Simpson et al., 2000). In addition, the knockdown of Robo3 in a Robo2 mutant background gives rise to one large medial axon bundle representing a fusion of all three FasII-positive fascicles, whereas Robo1 and Robo2 double mutants display a midline collapse phenotype, similar to that observed in Slit mutants (Kidd et al., 1999; Simpson et al., 2000). These observations strongly suggest that Robo 2 and Robo3 have critical roles in the proper lateral positioning of longitudinal tracts, and that the primary functions of Robol and Robo2 are to bar these axons from re-entering the midline. Accordingly, the role of Drosophila Robo3 appears to be analogous to that of vertebrate Robol and Robo2, whereas vertebrate Robo3 (Rig-1) operates in a manner similar to Drosophila Commissureless, by facilitating the passage of commissural axons across the ventral midline (Seeger et al., 1993; Keleman et al., 2002; Sabatier et al., 2004; Chen et al., 2008).

Regarding the mechanism through which Robos regulate the lateral positioning of longitudinal axons, it has recently been established that structural differences between Robo receptors do not have a crucial role in this process (Spitzweck et al., 2010). Rather, the gene expression profile of each Robo controls longitudinal axon sorting. This was elegantly demonstrated by replacing the genomic loci of each Robo with full length Robo sequences through homologous recombination and assessing the effects of these manipulations on longitudinal axon pathfinding (Spitzweck et al., 2010). Together, the findings strongly suggest that the timing, location, and/or level of each Robo gene are essential for achieving proper sorting of longitudinal axons in Drosophila ventral nerve cord.

Thus far, the role of the Robo ligand Slit, which operates as a potent repulsive guidance cue for a variety of invertebrate and vertebrate axons (Mastick et al., 2010; Ypsilanti et al., 2010), in the lateral positioning of longitudinal tracts has not been clearly established within the Drosophila ventral nerve cord. Although multiple populations of axons collapse on the midline in Slit mutants (Battye et al., 1999; Kidd et al., 1999), and the overexpression of Slit in midline glia cells disrupts the pathfinding of 
commissural axons (Battye et al., 1999), the role(s) of Slit in regulating the guidance of post-crossing commissural axons has not been explicitly addressed (Dickson and Gilestro, 2006). In contrast, and as discussed above, Slits appear to regulate the sorting of longitudinal axons in the embryonic mouse spinal cord.

\section{THE ROLE OF AXON FASCICULATION IN THE FORMATION OF LONGITUDINAL TRACTS WITHIN THE INVERTEBRATE CNS}

The dynamic roles of axon fasciculation and defasciculation events on the pathfinding of longitudinally projecting axons were originally demonstrated in grasshopper embryos (Raper et al., 1983, 1984; Harrelson and Goodman, 1988; Raper and Mason, 2010). The observation that precise fasciculation patterns exist among populations of longitudinally projecting axons led to the identification of molecules that are selectively expressed on particular longitudinal tracts in Drosophila. One major class of fasciculation molecules is the IgCAM superfamily members, of which FasII is an example (Grenningloh et al., 1991). In the ventral nerve cord of Drosophila FasII mutants, intermediate and lateral fascicles are conspicuously defasciculated, and forced expression of FasII leads to partially fused longitudinal fascicles (Lin et al., 1994). These results support a role for FasII in mediating the fasciculation of longitudinally projecting axons in Drosophila. Notably, however, defasciculated or hyperfasciculated axons in genetically manipulated FasII embryos retain their ability to appropriately project along the A-P axis adjacent to the midline (Lin et al., 1994). Thus, it appears that FasII does not explicitly control the directed growth/pathfinding of longitudinal axons along the A-P axis of the Drosophila ventral nerve cord.

The classical cadherins represent another major class of CAMs, and N-cadherin, in particular, has been implicated in the fasciculation of FasII-positive axons and their assembly into longitudinal axon tracts (Iwai et al., 1997). N-cadherin is expressed broadly in the Drosophila CNS, with particularly high levels present on axons, and $\mathrm{N}$-cadherin mutants display defects in the bundling and pathfinding of FasII-positive intermediate and lateral fascicles (Iwai et al., 1997). Reminiscent of the FasII mutant phenotype, the majority of improperly fasciculated axons appropriately project along the A-P axis in Drosophila $\mathrm{N}$-cadherin mutants. Interestingly, the observed defects appear quite selective and specific given that $\mathrm{N}$-cadherin is broadly and robustly expressed on axons within the Drosophila ventral nerve cord. To further dissect the role of $\mathrm{N}$-cadherin in longitudinal tract formation, the pathfinding behavior of a genetically distinct population of neurons, defined by the expression of LIM homeodomain transcription factor, Apterous, was examined in $\mathrm{N}$-cadherin null mutants. Axons extending from Apterous-positive neurons normally fasciculate tightly with each other and project ipsilaterally in the anterior direction along the most medial edge of the Drosophila ventral nerve cord (Lundgren et al., 1995). However, in $N$-cadherin mutants, these axons fail to fasciculate, and the dorsal-most axons project slightly lateral to their normal medial tract. Despite these defects Apterous axons continue to project rostrally in $N$-cadherin mutants (Iwai et al., 1997), indicating that like FasII, N-cadherin does not regulate this pathfinding decision. Notably, the perturbations in the pathfinding of N-cadherin-lacking Apterous axons resemble the defective fasciculation of these axons observed in Apterous mutants (Lundgren et al., 1995), raising the possibility that Apterous regulates $\mathrm{N}$-cadherin expression/function. Overall, these studies suggest that although $\mathrm{N}$-cadherin might not be required for the directed growth of axons along the A-P axis, it does ensure the fidelity of longitudinal axon tract formation in Drosophila.

In addition to the CAMs, Semas, which are cell surface or secreted molecules, and their receptors, the Plexins have been implicated in the formation of longitudinal axon tracts within the Drosophila CNS. For example, transmembrane Sema1A and its receptor PlexinA regulate the defasciculation of FasII-labeled laterally positioned longitudinal axons from their neighboring intermediate fascicles (Winberg et al., 1998; Yu et al., 1998). Specifically, the lateral fascicle in Sema1A or PlexinA mutants is disrupted and fused with the intermediate fascicle, and PlexinA regulates this process via repulsive signaling. These mutant phenotypes likely reflect defects in defasciculation, rather than fasciculation, since the lateral fascicle-associated axons apparently fail to break away from the intermediate fascicle (Winberg et al., 1998). Whereas transmembrane Sema1A-PlexA signaling selectively controls the assembly of laterally positioned FasII-positive axons into longitudinal tracts, secreted Sema2A and Sema2B appear to regulate the bundling of axons in the FasII-labeled intermediate fascicle, through the actions of PlexinB receptors (Wu et al., 2011). In a key recent study, it has been shown that in Sema2A; Sema2B double and PlexinB mutants, FasII-positive axons in intermediate fascicles defasciculate from each other and these tracts are severely disorganized (Wu et al., 2011). Here, Sema2A likely creates a repulsive boundary that constrains the positioning and growth of the intermediate fascicle. On the other hand, Sema2B facilitates the fasciculation of these axons, by acting as a short-range attractive cue (Wu et al., 2011). PlexinB is expressed at high levels in the region of the neuropile that contains intermediate and lateral tracts, and is also likely present on the first set of pioneer axons, which form the FasII-positive intermediate fascicle (Wu et al., 2011). Therefore, it appears that PlexinB controls the formation of the intermediate longitudinal fascicle by transducing Sema2A-dependent repulsive signals and Sema2B-mediated attraction (Wu et al., 2011).

In the Drosophila CNS, longitudinal axon tracts receive direct innervation from sensory axons (Boyan and Ball, 1993). Interestingly, PlexinB signaling activated by Sema2A and Sema2B also regulates the targeting of genetically distinct mechanosensory axons to the FasII-positive intermediate fascicle (Wu et al., 2011). Specifically, in Sema2A; Sema2B double or PlexinB mutant lines, particular mechanosensory axons fail to innervate axons located in the FasII-labeled intermediate fascicle. Since PlexinB appears to regulate the targeting of these mechanosensory axons in a cell autonomous manner, the failure of this sensory axon innervation is not the result of the defasciculation of the intermediate fascicleassociated axons, which has been observed in these mutant lines as mentioned above (Wu et al., 2011). This finding raises the possibility that targeting of other longitudinal fascicles to appropriate sensory axons is also coordinately regulated by Semas and their Plexin receptors.

Although these studies clearly show that the fasciculation of longitudinal tracts is tightly regulated by specific sets 
and combinations of guidance molecules the consequences of the defective fasciculation events remain poorly understood. Ultimately, disrupted patterns of fasciculation might be expected to promote mis-targeting or defects in the pre-synaptic termination patterns on a given fascicle.

\section{TARGETING OF LONGITUDINAL AXONS IN THE VERTEBRATE CNS}

In contrast to the progress made in identifying molecules and mechanisms that regulate the pathfinding of longitudinal axons in the vertebrate CNS, considerably less is known about what controls the targeting of these axons. Although it is generally assumed that mis-directed axons, which pathfind along aberrant trajectories, will ultimately fail to reach their appropriate targets, this may not always be the case (see examples above). Accordingly, identifying the synaptic targets of longitudinally projecting axons and elucidating the molecular mechanisms that control the targeting of these axons should clarify key aspects of neural circuit formation in wild type and mutant phenotypes. Part of the lack of progress in elucidating mechanisms that control axon targeting can most likely be attributed to the technical limitations associated with tracing axons over long distances. For example, since many axonal tracers have slow diffusion rates in fixed tissue (Vercelli et al., 2000), these reagents would have to be delivered in vivo or into appropriate in vitro preparations to label the full extent of longitudinal axon tracts, and these are not always feasible options. In addition, pan-axonal tracers, such as DiI, are incapable of reliably and reproducibly labeling specific populations of axons and, thus it has not been possible to visualize particular sets of axons over long distances and assess the consequences of molecular perturbations on their pathfinding and targeting. Analogous to approaches that are routinely employed in invertebrate systems, recently developed genetically labeling strategies have now made it possible to visualize, and study the targeting of, long-range longitudinal projections within the vertebrate CNS.

\section{ASCENDING LONGITUDINALLY PROJECTING SPINAL AXONS}

Along with the technical limitations described above, the bilateral symmetry of the spinal cord and presence of both ipsilateral and commissural axons within the major longitudinal axon tracts of the marginal zone also confound attempts to visualize these long-range projections. The ascending spinal longitudinal tracts, in particular, are largely bilaterally symmetric with both sides of the LF and VF, but not the DF, containing contralaterally and ipsilaterally projecting axons (Kerr, 1975; Matsushita and Hosoya, 1979; Giesler et al., 1984; Burstein et al., 1990; Katter et al., 1991; Yezierski and Mendez, 1991). In addition, some of the component axons, such as those that compose the spinocerebellar tract, re-cross the midline in the cerebellum (Matsushita and Hosoya, 1979; Matsushita and Ikeda, 1980; Brodal, 1998). Accordingly, unilateral labeling carried out in intact animals is required to obtain unobstructed views of ascending longitudinal axons, and to assess the consequences of molecular/genetic manipulations on their pathfinding and targeting.

Unilateral labeling of axons in vivo can be achieved via the use of, in ovo and in utero unilateral electroporation strategies, in chick and mouse embryos, respectively, (Krull, 2004; Saito, 2006; Petros et al., 2009). In fact, in ovo electroporation of a pan-axonal reporter, has been used to show that both commissural and ipsilateral axons originating from a specific segment of the spinal cord (lumbosacral level 2) project rostrally to a common target, the cerebellum, in the E8-E13 chick brain (Arakawa et al., 2008).

To investigate the mechanisms that control the pathfinding and targeting of particular classes of spinal projection neurons, it is critical to first develop labeling methods that can be used to visualize genetically distinct populations of these neurons/axons. Dorsal spinal neurons represent a well-studied and major class of projection neurons (Nunes and Sotelo, 1985; Burstein et al., 1990; Yezierski and Mendez, 1991; Brodal, 1998), and subtypes of these neurons have been defined on the basis of transcription factor expression profiles (Helms and Johnson, 2003). For example, d1 dorsal spinal neurons are derived from progenitors that express the basic helix-loop-helix (bHLH) transcription factor Atoh1 (formerly Math1), and express the homeodomain (HD) transcription factors, Lhx2, Lhx9, BarH1, and Brn3a (Helms and Johnson, 2003). On the other hand, Neurog1- (bHLH family member) positive progenitors give rise to $\mathrm{d} 2$ neurons, which are defined by the expression of Lhx1, Lhx5, FoxD3, and Brn3a (Helms and Johnson, 2003). Based on these observations, a variety of transgenic reporter mice were generated to facilitate the mechanisms that control the development of $\mathrm{d} 1$ and $\mathrm{d} 2$ dorsal spinal neurons (Helms and Johnson, 1998; Nakada et al., 2004; Machold and Fishell, 2005; Saba et al., 2005; Wilson et al., 2008). However, the bilateral symmetry of the reporter gene expression patterns and the presence of endogenous labeling in the brain, has hampered the definitive identification of $\mathrm{d} 1$ and $\mathrm{d} 2$ targets (Helms and Johnson, 1998; Bermingham et al., 2001; Nakada et al., 2004; Saba et al., 2005). Nevertheless, DiI labeling in an Aoth1-lacZ knock-in (null for Atoh1) mouse line was carried out in an attempt to identify the brain targets of $\mathrm{d} 1$ neurons/axons (Bermingham et al., 2001). This study reported that the size of the DiI-labeled spinocerebellar tract within the hindbrain was reduced in Atoh $1^{\text {lac } / \text { lacZ }}$ mice compared to wild type and heterozygous littermates, raising the possibility that $\mathrm{d} 1$ axons target the cerebellum (Bermingham et al., 2001). More recently we have delivered Atoh1 and Neurog1 reporter constructs (Lumpkin et al., 2003; Nakada et al., 2004; Reeber et al., 2008) into the embryonic chick spinal cord via unilateral in ovo electroporation and achieved reproducible labeling of longitudinally projecting $\mathrm{d} 1$ and $\mathrm{d} 2$ axons. Moreover, we have found that both of these projection neurons target a variety of brain regions, including the cerebellum (N.S. and Z.K., unpublished observations). These observations support the feasibility of using genetic labeling strategies to visualize the long-range projections of genetically distinct spinal projection neurons and to carry out detailed analyses of spinal axon targeting in an in vivo setting.

\section{DESCENDING CORTICOSPINAL AXONS}

Anatomical considerations suggest that the targeting of descending corticospinal axons is somatotopically regulated, since collaterals of the primary corticospinal axons exit the DF and innervate the spinal cord gray matter at specific positions along the rostrocaudal axis (O'Leary and Koester, 1993; Kuang and Kalil, 1994). 
The PSA modification of NCAM (PSA-NCAM) appears to facilitate collateral formation by modifying the fasciculation state of corticospinal axons within the DF (Daston et al., 1996). Whereas NCAM is expressed all along pathfinding corticospinal axons, PSA-NCAM is selectively present in the DF, where collateral formation occurs. Removal of PSA through enzymatic degradation reduces the number of collaterals at particular levels of the spinal cord (Daston et al., 1996). Despite these observations, exactly how the formation of axon collaterals is somatotopically regulated at specific segments of the spinal cord remains poorly defined.

Although corticospinal tracts are composed of ipsilateral and contralateral projections located rostral and caudal to the pyramidal decussation, respectively, the component axons retain their unilaterality on either side of the spinal cord (Stanfield, 1992). Accordingly, unilateral labeling strategies, like those we have used to visualize ascending spinal projection neuron tracts (see above), should not necessarily be required to elucidate the mechanisms that control corticospinal axon targeting in the spinal cord. Rather, transgenic reporter mice that can be used to visualize corticospinal tract axons (Bareyre et al., 2005) should be sufficient. In this regard, the recent use of corticospinal axon-specific reporter mice has led to the identification of Clark's column neurons, which contribute to the spinocerebellar projection, as targets of corticospinal axons (Hantman and Jessell, 2010). This new and important observation will likely facilitate a detailed investigation into the molecular mechanisms that control the guidance and targeting of corticospinal axons.

\section{SUMMARY AND PERSPECTIVE}

Just as longitudinally projecting axons must travel long distances in order to reach their synaptic targets and to transmit information between disparate regions of the CNS and from the environment to the brain, we have a long way to go before acquiring even a superficial understanding of the underlying

\section{REFERENCES}

Arakawa, T., Iwashita, M., Matsuzaki, F., Suzuki, T., and Yamamoto, T. (2008). Paths, elongation, and projections of ascending chick embryonic spinal commissural neurons after crossing the floor plate. Brain Res. 1223, 25-33.

Avraham, O., Hadas, Y., Vald, L., Hong, S., Song, M. R., and Klar, A. (2010). Motor and dorsal root ganglion axons serve as choice points for the ipsilateral turning of $\mathrm{dI} 3$ axons. $J$. Neurosci. 30, 15546-15557.

Avraham, O., Hadas, Y., Vald, L., Zisman, S., Schejter, A., Visel, A., and Klar, A. (2009). Transcriptional control of axonal guidance and sorting in dorsal interneurons by the Lim-HD proteins Lhx9 and Lhx1. Neural Dev. 4, 21.

Bagri, A., Marín, O., Plump, A. S., Mak, J., Pleasure, S. J., Rubenstein, J. L., and Tessier-Lavigne, M. (2002). Slit proteins prevent midline crossing and determine the dorsoventral

guidance and targeting mechanisms. Despite the recent progress made in elucidating mechanisms that control particular phases of longitudinal axon growth/targeting in specific model vertebrate and invertebrate systems, many fundamental "big picture" questions remain. For example: (1) Do morphogens have central roles in longitudinal axon guidance and/or targeting or are they only required to set the polarity of axons as they turn into the longitudinal plane? (2) Do the mechanisms that control longitudinal axon guidance also control the targeting of these axons? (3) Do short-range axon-axon interactions on their own facilitate the formation of precisely positioned longitudinal axon tracts or is the directed and stereotypical growth of longitudinal tracts controlled by a complex interplay between long-range and short-range/adhesive guidance systems? (4) Does the same molecular logic control the guidance and targeting of ipsilateral and commissural axons and/or the formation of ascending and descending axonal tracts? (... as discussed above the answer seems to be a resounding no) (5) Are the mechanisms that control the long-range pathfinding and targeting of longitudinally projecting axons conserved across species and organisms? As we have suggested above, obtaining the answers to these and other burning questions in the field will require that state-of-the-art genetic labeling strategies initially be used, in mouse and chick embryos as well as in Drosophila and C. elegans, to carefully map the projection patterns of longitudinal axons and to identify their synaptic targets. Once this has been achieved, a combination of complementary gain- and loss-of-function manipulations in the various model systems should, ultimately, make it possible to elucidate the molecular logic that controls longitudinal axon guidance and targeting. Importantly, these likely to be tedious, time-consuming and ground breaking studies will surely provide exciting new insights into neural circuit formation across species and the molecular genetic underpinnings of neurological dysfunction.

in the brain: an update. Trends Neurosci. 30, 194-202.

Bourikas, D., Pekarik, V., Baeriswyl, T., Grunditz, A., Sadhu, R., Nardo, M., and Stoeckli, E. T. (2005). Sonic hedgehog guides commissural axons along the longitudinal axis of the spinal cord. Nat. Neurosci. 8, 297-304.

Bovolenta, P. (2005). Morphogen signaling at the vertebrate growth cone: a few cases or a general strategy? J. Neurobiol. 64, 405-416.

Bovolenta, P., and Dodd, J. (1990). Guidance of commissural growth cones at the floor plate in embryonic rat spinal cord. Development 109, 435-447.

Boyan, G. S., and Ball, E. E. (1993). The grasshopper, Drosophila and neuronal homology (advantages of the insect nervous system for the neuroscientist). Prog. Neurobiol. 41, 657-682.

Brodal, P. (1998). The Central Nervous System: Structure and Function.
New York, NY: Oxford University Press, Inc.

Burstein, R., Dado, R. J., and Giesler, G. J. Jr. (1990). The cells of origin of the spinothalamic tract of the rat: a quantitative reexamination. Brain Res. 511, 329-337.

Burt, A. M. (1993). Textbook of Neuroanatomy. Philadelphia, PA: W. B. Saunders Co.

Castellani, V., Chedotal, A., Schachner, M., Faivre-Sarrailh, C., and Rougon, G. V. (2000). Analysis of the L1deficient mouse phenotype reveals cross-talk between Sema3A and L1 signaling pathways in axonal guidance. Neuron 27, 237-249.

Charron, F. D. R., and Tessier-Lavigne, M. (2005). Novel brain wiring functions for classical morphogens: a role as graded positional cues in axon guidance. Development 132, 2251-2262.

Chen, Z., Gore, B. B., Long, H., Ma, L., and Tessier-Lavigne, M. (2008). Alternative splicing of the Robo3 
axon guidance receptor governs the midline switch from attraction to repulsion. Neuron 58, 325-332.

Cohen, N. R., Taylor, J. S. H., Scott, L. B., Guillery, R. W., Soriano, P., and Furley, A. J. W. (1997). Errors in corticospinal axon guidance in mice lacking the neural cell adhesion molecule L1. Curr. Biol. 8, 26-33.

Dahme, M., Bartsch, U., Martini, R., Anliker, B., Schachner, M., and Mantei, N. (1997). Disruption of the mouse L1 gene leads to malformations of the nervous system. Nat. Genet. 17, 346-349.

Daston, M. M., Bastmeyer, M., Rutishauser, U., and O'Leary, D. D. M. (1996). Spatially restricted increase in polysialic acid enhances corticospinal axon branching related to target recognition and innervation. J. Neurosci. 16, 5488-5497.

Dickson, B. J., and Gilestro, G. F. (2006). Regulation of commissural axon pathfinding by slit and its Robo receptors. Annu. Rev. Cell Dev. Biol. 22, 651-675.

Dickson, B. J., and Zou, Y. (2010). Navigating intermediate targets: the nervous system midline. Cold Spring Harb. Perspect. Biol. 2, a002055.

Domanitskaya, E., Wacker, A., Mauti, O., Baeriswyl, T., Esteve, P. Bovolenta, P., and Stoeckli, E. T. (2010). Sonic hedgehog guides post-crossing commissural axons both directly and indirectly by regulating Wnt activity. J. Neurosci. 30, 11167-11176.

Dottori, M., Hartley, L., Galea, M., Paxinos, G., Polizzotto, M., Kilpatrick, T., Bartlett, P. F., Murphy, M., Kontgen, F., and Boyd, A. W. (1998). EphA4 (Sek1) receptor tyrosine kinase is required for the development of the corticospinal tract. Proc. Natl. Acad. Sci. U.S.A. 95, 13248-13253.

Dugan, J. P., Stratton, A., Riley, H. P., Farmer, W. T., and Mastick, G. S. (2011). Midbrain dopaminergic axons are guided longitudinally through the diencephalon by Slit/Robo signals. Mol. Cell. Neurosci. 46, 347-356.

Farmer, W. T., Altick, A. L., Nural, H. F., Dugan, J. P., Kidd, T., Charron, F., and Mastick, G. S. (2008). Pioneer longitudinal axons navigate using floor plate and Slit/Robo signals. Development 135, 3643-3653.

Faulkner, R. L., Low, L. K., Liu, X. B., Coble, J., Jones, E. G., and Cheng, H. J. (2008). Dorsal turning of motor corticospinal axons at the pyramidal decussation requires plexin signaling. Neural Dev. 3, 21
Fenstermaker, A. G., Prasad, A. A., Bechara, A., Adolfs, Y., Tissir, F., Goffinet, A., Zou, Y., and Pasterkamp, R. J. (2010). Wnt/planar cell polarity signaling controls the anterior-posterior organization of monoaminergic axons in the brainstem. J. Neurosci. 30, 16053-16064.

Finger, J. H., Bronson, R. T., Harris, B. Johnson, K., Przyborski, S. A., and Ackerman, S. L. (2002). The netrin 1 receptors Unc5h3 and Dcc are necessary at multiple choice points for the guidance of corticospinal tract axons. J. Neurosci. 22, 10346-10356.

Giesler, G. J., Nahin, R. L., and Madsen, A. M. (1984). Postsynaptic dorsal column pathway of the rat. I. Anatomical studies. J. Neurophysiol. 51, 260-275

Giesler, G. J. Jr., Spiel, H. R., and Willis, W. D. (1981). Organization of spinothalamic tract axons within the rat spinal cord. J. Comp. Neurol. 195, 243-252.

Grenningloh, G., Jay Rehm, E., and Goodman, C. S. (1991). Genetic analysis of growth cone guidance in Drosophila: fasciclin II functions as a neuronal recognition molecule. Cell $67,45-57$

Hantman, A. W., and Jessell, T. M. (2010). Clarke's column neurons as the focus of a corticospinal corollary circuit. Nat. Neurosci. 13, 1233-1239.

Harrelson, A., and Goodman, C. (1988). Growth cone guidance in insects: fasciclin II is a member of the immunoglobulin superfamily. Science 242, 700-708.

Helms, A. W., and Johnson, J. E. (1998). Progenitors of dorsal commissural interneurons are defined by Math1 expression. Development 125, 919-928.

Helms, A. W., and Johnson, J. E. (2003). Specification of dorsal spinal cord interneurons. Curr. Opin. Neurobiol. $13,42-49$.

Hilliard, M. A., and Bargmann, C. I. (2006). Wnt signals and frizzled activity orient anterior-posterior axon outgrowth in C. elegans. Dev. Cell 10, 379-390.

Imondi, R., and Kaprielian, Z. (2001). Commissural axon pathfinding on the contralateral side of the floor plate: a role for B-class ephrins in specifying the dorsoventral position of longitudinally projecting commissural axons. Development 128, 4859-4871.

Imondi, R., Wideman, C., and Kaprielian, Z. (2000). Complementary expression of transmembrane ephrins and their receptors in the mouse spinal cord: a possible role in constraining the orientation of longitudinally projecting axons. Development 127, 1397-1410.

Iwai, Y., Usui, T., Hirano, S., Steward, R., Takeichi, M., and Uemura, T. (1997). Axon patterning requires DN-cadherin, a novel neurona adhesion receptor, in the Drosophila embryonic CNS. Neuron 19, 77-89.

Jaworski, A., Long, H., and TessierLavigne, M. (2010). Collaborative and specialized functions of Robol and Robo2 in spinal commissural axon guidance. J. Neurosci. 30 , 9445-9453.

Kadison, S. R., and Kaprielian, Z (2004). Diversity of contralateral commissural projections in the embryonic rodent spinal cord. $J$. Comp. Neurol. 472, 411-422.

Katter, J. T., Burstein, R., and Giesler G. J. (1991). The cells of origin of the spinohypothalamic tract in cats. J. Comp. Neurol. 303, 101-112.

Keleman, K., Rajagopalan, S., Cleppien, D., Teis, D., Paiha, K., Huber, L. A. Technau, G. M., and Dickson, B. J. (2002). Comm sorts robo to control axon guidance at the Drosophila midline. Cell 110, 415-427.

Kerr, F. W. L. (1975). The ventra spinothalamic tract and other ascending systems of the ventral funiculus of the spinal cord. $J$. Comp. Neurol. 159, 335-355.

Kidd, T., Bland, K. S., and Goodman, C. S. (1999). Slit is the midline repellent for the robo receptor in Drosophila. Cell 96, 785-794.

Kiehn, O. (2006). Locomotor circuits in the mammalian spinal cord. Annu. Rev. Neurosci. 29, 279-306.

Kolk, S. M., Gunput, R. A., Tran, T. S., van den Heuvel, D. M. Prasad, A. A., Hellemons, A. J. Adolfs, Y., Ginty, D. D., Kolodkin A. L., Burbach, J. P., Smidt, M. P., and Pasterkamp, R. J. (2009). Semaphorin $3 \mathrm{~F}$ is a bifunctiona guidance cue for dopaminergic axons and controls their fasciculation, channeling, rostral growth, and intracortical targeting. $J$ Neurosci. 29, 12542-12557.

Krull, C. E. (2004). A primer on using in ovo electroporation to analyze gene function. Dev. Dyn. 229, 433-439.

Kuang, R. Z., and Kalil, K. (1994) Development of specificity in corticospinal connections by axon collaterals branching selectively into appropriate spinal targets. J. Comp. Neurol. 344, 270-282.

Kullander, K., Butt, S. J., Lebret, J. M., Lundfald, L., Restrepo, C. E., Rydstrom, A., Klein, R., and Kiehn, O. (2003). Role of EphA4 and EphrinB3 in local neuronal circuits that control walking. Science 299, 1889-1892.

Kullander, K., Croll, S. D., Zimmer, M., Pan, L., McClain, J., Hughes, V., Zabski, S., Dechiara, T. M., Klein, R. D., Yancopoulos, G. D., and Gale, N. W. (2001a). Ephrin-B3 is the midline barrier that prevents corticospinal tract axons from recrossing, allowing for unilateral motor control. Genes Dev. 15, 877-888.

Kullander, K., Mather, N. K., Diella, F., Dottori, M., Boyd, A. W., and Klein, R. D. (2001b). Kinase-dependent and kinase-independent functions of EphA4 receptors in major axon tract formation in vivo. Neuron 29 73-84.

Lin, D. M., Fetter, R. D., Kopczynski, C., Grenningloh, G., and Goodman, C. S. (1994). Genetic analysis of fasciclin II in Drosophila: defasciculation, refasciculation, and altered fasciculation. Neuron 13, 1055-1069.

Liu, Y., Shi, J., Lu, C. C., Wang, Z. B., Lyuksyutova, A. I., Song, X. J., and Zou, Y. (2005). Ryk-mediated Wnt repulsion regulates posteriordirected growth of corticospinal tract. Nat. Neurosci. 8, 1151-1159.

Long, H., Sabatier, C., Ma, L., Plump, A., Yuan, W., Ornitz, D. M., Tamada, A., Murakami, F., Goodman, C. S., and TessierLavigne, M. (2004). Conserved roles for Slit and Robo proteins in midline commissural axon guidance. Neuron 42, 213-223.

Lopez-Bendito, G., Flames, N., Ma, L., Fouquet, C., Di Meglio, T., Chedotal, A., Tessier-Lavigne, M., and Marin, O. (2007). Robol and Robo2 cooperate to control the guidance of major axonal tracts in the mammalian forebrain. $J$ Neurosci. 27, 3395-3407.

Lumpkin, E. A., Collisson, T., Parab, P., Omer-Abdalla, A., Haeberle, H., Chen, P., Doetzlhofer, A., White, P., Groves, A., Segil, N., and Johnson, J. E. (2003). Math1-driven GFP expression in the developing nervous system of transgenic mice Gene Expr. Patterns 3, 389-395.

Lundgren, S. E., Callahan, C. A., Thor, S., and Thomas, J. B. (1995). Control of neuronal pathway selection by the Drosophila LIM homeodomain gene apterous. Development 121, 1769-1773.

Lyuksyutova, A. I., Lu, C.-C., Milanesio, N., King, L. A., Guo, N., Wang, Y., Nathans, J., Tessier-Lavigne, M., and Zou, Y. (2003). Anterior-posterior guidance of commissural axons by Wnt-frizzled signaling. Science 302, 1984-1988.

Machold, R., and Fishell, G. (2005). Math1 is expressed in temporally 
discrete pools of cerebellar rhombic-lip neural progenitors. Neuron 48, 17-24.

Mastick, G. S., Farmer, W. T., Altick, A. L., Nural, H. F., Dugan, J. P., Kidd, T., and Charron, F. (2010). Longitudinal axons are guided by Slit/Robo signals from the floor plate. Cell Adh. Migr. 4, 337-341.

Matsushita, M., and Hosoya, Y. (1979). Cells of origin of the spinocerebellar tract in the rat, studied with the method of retrograde transport of horseradish peroxidase. Brain Res. $173,185-200$.

Matsushita, M., and Ikeda, M. (1980). Spinocerebellar projections to the vermis of the posterior lobe and the paramedian lobule in the cat, as studied by retrograde transport of horseradish peroxidase. J. Comp. Neurol. 192, 143-162.

Nakada, Y., Parab, P., Simmons, A., Omer-Abdalla, A., and Johnson, J. E. (2004). Separable enhancer sequences regulate the expression of the neural bHLH transcription factor neurogenin 1. Dev. Biol. 271, 479-487.

Nunes, M. L. A., and Sotelo, C. (1985). Development of the spinocerebellar system in the postnatal rat. J. Comp. Neurol. 237, 291-306.

O'Leary, D. D. M., and Koester, S. E. (1993). Development of projection neuron types, axon pathways, and patterned connections of the mammalian cortex. Neuron 10, 991-1006.

Pan, C. L., Howell, J. E., Clark, S. G., Hilliard, M., Cordes, S., Bargmann, C. I., and Garriga, G. (2006). Multiple Wnts and frizzled receptors regulate anteriorly directed cell and growth cone migrations in Caenorhabditis elegans. Dev. Cell 10, 367-377.

Petros, T. J., Rebsam, A., and Mason, C. A. (2009). In utero and ex vivo electroporation for gene expression in mouse retinal ganglion cells. J. Vis. Exp. 24, e1333.

Rajagopalan, S., Vivancos, V., Nicolas, E., and Dickson, B. J. (2000). Selecting a longitudinal pathway: Robo receptors specify the lateral position of axons in the Drosophila CNS. Cell 103, 1033-1045.

Raper, J., Bastiani, M., and Goodman, C. (1983). Pathfinding by neuronal growth cones in grasshopper embryos. II. Selective fasciculation onto specific axonal pathways. J. Neurosci. 3, 31-41.

Raper, J., Bastiani, M., and Goodman, C. (1984). Pathfinding by neuronal growth cones in grasshopper embryos. IV. The effects of ablating the $\mathrm{A}$ and $\mathrm{P}$ axons upon the behavior of the $\mathrm{G}$ growth cone. $J$. Neurosci. 4, 2329-2345.

Raper, J., and Mason, C. (2010). Cellular strategies of axonal pathfinding. Cold Spring Harb. Perspect. Biol. 2, a001933.

Reeber, S. L., Sakai, N., Nakada, Y., Dumas, J., Dobrenis, K., Johnson, J. E., and Kaprielian, Z. (2008). Manipulating Robo expression in vivo perturbs commissural axon pathfinding in the chick spinal cord. J. Neurosci. 28, 8698-8708.

Rolf, B., Bastmeyer, M., Schachner, M., and Bartsch, U. (2002). Pathfinding errors of corticospinal axons in neural cell adhesion moleculedeficient mice. J. Neurosci. 22, 8357-8362.

Runker, A. E., Little, G. E., Suto, F., Fujisawa, H., and Mitchell, K. J. (2008). Semaphorin-6A controls guidance of corticospinal tract axons at multiple choice points. Neural Dev. 3, 34.

Saba, R., Johnson, J. E., and Saito, T. (2005). Commissural neuron identity is specified by a homeodomain protein, Mbhl, that is directly downstream of Math1. Development 132, 2147-2155.

Sabatier, C., Plump, A. S., Le, M., Brose, K., Tamada, A., Murakami, F., Lee, E. Y. H. P., and TessierLavigne, M. (2004). The divergent Robo family protein Rig-1/Robo3 is a negative regulator of slit responsiveness required for midline crossing by commissural axons. Cell 117, 157-169.

Saito, T. (2006). In vivo electroporation in the embryonic mouse central nervous system. Nat. Protoc. 1 , 1552-1558.

Sánchez-Camacho, C., and Bovolenta, P. (2009). Emerging mechanisms in morphogen-mediated axon guidance. Bioessays 31, 1013-1025.

Seeger, M., Tear, G., Ferres-Marco, D., and Goodman, C. S. (1993). Mutations affecting growth cone guidance in Drosophila: genes necessary for guidance toward or away from the midline. Neuron 10, 409-426.

Shafer, B., Onishi, K., Lo, C., Colakoglu, G., and Zou, Y. (2011). Vangl2 promotes Wnt/planar cell polaritylike signaling by antagonizing Dvl1mediated feedback inhibition in growth cone guidance. Dev. Cell 20, 177-191.

Sibbe, M., Taniguchi, M., Schachner, M., and Bartsch, U. (2007). Development of the corticospinal tract in Semaphorin3A- and CD24deficient mice. Neuroscience 150, 898-904.

Simpson, J. H., Bland, K. S., Fetter R. D., and Goodman, C. S. (2000) Short-range and long-range guidance by Slit and its Robo receptors: a combinatorial code of Robo receptors controls lateral position. Cell 103, 1019-1032.

Spitzweck, B., Brankatschk, M., and Dickson, B. J. (2010). Distinct protein domains and expression patterns confer divergent axon guidance functions for Drosophila Robo receptors. Cell 140, 409-420.

Stanfield, B. B. (1992). The development of the corticospinal projection. Prog. Neurobiol. 38, 169-202.

Tissir, F., and Goffinet, A. M. (2010). Planar cell polarity signaling in neural development. Curr. Opin. Neurobiol. 20, 572-577.

Vercelli, A., Repici, M., Garbossa, D. and Grimaldi, A. (2000). Recent techniques for tracing pathways in the central nervous system of developing and adult mammals. Brain Res. Bull. 51, 11-28.

Willis, W. D., Jr. (2007). The somatosensory system, with emphasis on structures important for pain. Brain Res. Rev. 55, 297-313.

Wilson, S. I., Shafer, B., Lee, K. J., and Dodd, J. (2008). A molecular program for contralateral trajectory: Rig-1 control by LIM homeodomain transcription factors. Neuron 59, 413-424.

Winberg, M. L., Noordermeer, J. N., Tamagnone, L., Comoglio, P. M. Spriggs, M. K., Tessier-Lavigne, M., and Goodman, C. S. (1998). Plexin $\mathrm{A}$ is a neuronal semaphorin receptor that controls axon guidance. Cell 95, 903-916.

Wu, Z., Sweeney, L. B., Ayoob, J. C., Chak, K., Andreone, B. J., Ohyama, T., Kerr, R., Luo, L., Zlatic, M., and Kolodkin, A. L. (2011). A combinatorial semaphorin code instructs the initial steps of sensory circuit assembly in the Drosophila CNS. Neuron 70, 281-298.

Xu, Q., and Grant, G. (1994). Course of spinocerebellar axons in the ventral and lateral funiculi of the spinal cord with projections to the anterior lobe: an experimental anatomical study in the cat with retrograde tracing techniques. J. Comp. Neurol. $345,288-302$

$\mathrm{Xu}$, Q., and Grant, G. (2005). Course of spinocerebellar axons in the ventral and lateral funiculi of the spinal cord with projections to the posterior cerebellar termination area: an experimental anatomical study in the cat, using a retrograde tracing technique. Exp. Brain Res. 162, 250-256.

Yamauchi, K., Mizushima, S., Tamada, A., Yamamoto, N., Takashima, S., and Murakami, F. (2009). FGF8 signaling regulates growth of midbrain dopaminergic axons by inducing semaphorin 3F. J. Neurosci. 29, 4044-4055.

Yezierski, R. P., and Mendez, C. M. (1991). Spinal distribution and collateral projections of rat spinomesencephalic tract cells. Neuroscience 44, 113-130.

Yokoyama, N., Romero, M. I., Cowan, C. A., Galvan, P., Helmbacher, F., Charnay, P., Parada, L. F., and Henkemeyer, M. (2001). Forward signaling mediated by ephrin-B3 prevents contralateral corticospinal axons from recrossing the spinal cord midline. Neuron 29 , 85-97.

Ypsilanti, A. R., Zagar, Y., and Chedotal, A. (2010). Moving away from the midline: new developments for Slit and Robo. Development 137, 1939-1952.

Yu, H.-H., Araj, H. H., Ralls, S. A., and Kolodkin, A. L. (1998). The transmembrane Semaphorin Sema I is required in Drosophila for embryonic motor and CNS axon guidance. Neuron 20, 207-220.

Zou, Y., and Lyuksyutova, A. I. (2007). Morphogens as conserved axon guidance cues. Curr. Opin. Neurobiol. 17, 22-28.

Conflict of Interest Statement: The authors declare that the research was conducted in the absence of any commercial or financial relationships that could be construed as a potential conflict of interest.

Received: 27 February 2012; accepted: 14 April 2012; published online: 04 May 2012.

Citation: Sakai $N$ and Kaprielian $Z$ (2012) Guidance of longitudinally projecting axons in the developing central nervous system. Front. Mol. Neurosci. 5:59. doi: 10.3389/fnmol.2012.00059 Copyright (c) 2012 Sakai and Kaprielian. This is an open-access article distributed under the terms of the Creative Commons Attribution Non Commercial License, which permits non-commercial use, distribution, and reproduction in other forums, provided the original authors and source are credited. 